\title{
Limb Lengthening with a Submuscular Locking Plate
}

\author{
Chang-Wug Oh, MD, PhD, Joon-Woo Kim, MD, PhD, Seung-Gil Baek, MD, Hee-Soo Kyung, MD, PhD, \\ and Hyun-Joo Lee, MD
}

Based on an original article: J Bone Joint Surg Br. 2009 Oct;91(10):1394-9.

\section{Introduction}

Limb lengthening with a submuscular locking plate provides a good alternative for patients, especially children, in whom lengthening over an intramedullary nail would be difficult.

Although distraction osteogenesis with an external fixator is widely used to treat limb-length discrepancy ${ }^{1-4}$, prolonged external fixation can cause many ity and stiffness, and refracture after fixator removal ${ }^{4-8}$. Lengthening over an intramedullary nail ${ }^{9-11}$ shortens the duration of external fixation, better protects distracted bone during the consolidation phase, and reduces rates of complications as compared with the use of an external fixator alone. In addition, this method allows patients to regain movement more quickly and return to activities of daily life in less time ${ }^{12,13}$. However, it is difficult to use an intramedullary nail when a patient has a narrow medullary canal, bone deformity, open physes, or joint contracture. In addition, intramedullary nailing of the femur may lead to femoral head osteonecrosis, especially when it is performed in children ${ }^{10}$. Submuscular fixation with a locking plate represents a recent advance in fracture treatment ${ }^{14}$ and has the advantages of providing angular stability and preserving the periosteal and endosteal blood supply ${ }^{15}$.

Limb lengthening with a submuscular locking plate is performed with the following four steps, with two operations (Video 1).

\section{Step 1: External Fixation for Lengthening} with Submuscular Plating

The first operation is divided into two steps, submuscular plating and external fixation with corticotomy; due to the anatomical characteristics, the procedures differ in the tibia and femur.

\section{Submuscular Plating}

In both the tibia and the femur, we prefer to fix a locking compression plate on the lateral side. The screws are fixed at the proximal segment, to permit lengthening of the distal segment.

\section{Tibial Lengthening (Figs. 1 through 7)}

- With the patient supine on a radiolucent table, make an incision 3 to $4 \mathrm{~cm}$ long in the area of Gerdy's tubercle at the proximal part of the tibia.

- Incise the iliotibial band and the tibialis anterior fascia and elevate muscle extraperiosteally.

- Make a submuscular tunnel along the lateral surface of the tibia with a periosteal surfer. If a periosteal surfer is not available, use the plate itself to make the tunnel.

- Avoid vigorous overretraction posteriorly, as this could damage the peroneal nerve.

- Choose a precontoured lateral plate so that at least three holes are available past the planned osteotomy site after the lengthening is complete.

- Insert the plate into the prepared submuscular tunnel extraperiosteally.

- Insert four or five locking screws into the proximal portion of the plate without damaging the physis.

\section{Femoral Lengthening (Figs. 8 through 13)}

- With the patient supine or in a lateral position on a radiolucent table, make an incision of 3 to $4 \mathrm{~cm}$ along the lateral aspect of the greater trochanter.

- Make a straight skin incision and perform underlying soft-tissue dissection.

- After incising the iliotibial tract and vastus lateralis fascia, dissect the vastus lateralis muscle.

- Make a submuscular tunnel along the lateral 
surface of the femur as described for tibial lengthening above.

- Select a straight 4.5-mm locking compression plate long enough to allow the required lengthening. Choose a plate with an anterior bow. Contour the chosen plate along the lateral surface of the femur.

- Insert the plate along the lateral surface of the femur through the submuscular tunnel.

- Using three or four locking screws, fix the plate to the proximal segment.

- In some cases, the use of a flexible intramedullary nail helps stabilize the distal segment and prevent angular deformity while the lengthening is taking place.

\section{External Fixation with Corticotomy}

- Apply an external fixator with a lengthening frame. For tibial lengthening, fix the monolateral frame to the medial side of each segment using three half-pins.

- For femoral lengthening, fix the three half-pins to the lateral side of each segment, proximal and distal to the preinserted plate. If needed, insert a flexible nail to stabilize the distal segment during lengthening.

- Alternatively, a circular frame can be used for both femoral and tibial lengthening.

- To avoid possible cross-contamination, while fixing the external fixator, take great care to ensure that the half-pins and wires used for external fixation do not contact the plate or screws.

- For tibial lengthening, perform a fibular osteotomy and use one or two 3.5-mm cortical screws to secure the distal tibiofibular joint.

- For the percutaneous corticotomy, make a $1-\mathrm{cm}$ second small incision located $1 \mathrm{~cm}$ below the distal screw of the proximal segment.

- Make multiple drill holes at the planned corticotomy site, followed by a complete corticotomy with a handheld osteotome. Ensure that the corticotomy site can be distracted manually under fluoroscopy.

- The corticotomy can be done either before or after the plating. If you do the corticotomy before the plating, make sure not to lose the reduction until the external fixation is finished. If you do it after the plating, direct the multiple drilling from the anterior cortex or the other cortex of the plate side. Make sure that the plate does not hinder the corticotomy procedure.

\section{Step 2: Lengthening}

Start distraction at seven to ten days after surgery and continue until the target length is achieved.

- Start distraction after seven to ten days of latency, to permit regeneration of the periosteal blood supply at the corticotomy site.

- Perform gradual distraction at a rate of $1 \mathrm{~mm}$ per day (distraction four times per day).

- Permit partial weight-bearing and physiotherapy to maintain the movements of adjacent joints.

- Obtain a radiograph weekly or every two weeks to monitor progress.

Step 3: Locking of the Distal Segment and Removal of the External Fixator

When the target length has been achieved, place screws into the distal segment through plate holes and remove the fixator.

- Drape the whole extremity and the applied external fixator together aseptically.

- Under fluoroscopic guidance, mark the empty plate holes of the distal segment for the planned screw fixation.

- Make a stab skin incision and perform gentle soft-tissue dissection.

- Place at least three bicortical screws (either cortical or locking) percutaneously through the plate into the distal segment.

- Sometimes, translation of the distal segment from the plate may be encountered. In this situation, fix the cortical screw through the plate hole first to obtain better alignment. Then, place the locking screws in the remaining holes.

- After completing screw fixation, close the wounds created by the screw fixation and remove the external fixator.

- Clean the wounds created by the external fixator pins and wires.

\section{Step 4: Postoperative Care}

Start with partial weight-bearing, obtain a radiograph every four to eight weeks, and allow full weight-bearing with crutches when osseous consolidation is observed.

- Start mobilization of the joints and partial weightbearing immediately after fixator removal.

- Obtain a radiograph every four to eight weeks until the distraction callus is fully consolidated.

- When signs of osseous consolidation are observed in at least three cortices on anteroposterior and lateral radiographs, allow the patient to walk with full weight-bearing and use of crutches. The patient should be slowly weaned off the crutches as tolerated. 


\section{Results}

We prospectively performed limb lengthening using an external fixator and a submuscular locking plate in ten patients ${ }^{16}$. The mean amount of lengthening achieved was $4.0 \mathrm{~cm}$ (range, 3.2 to $5.5 \mathrm{~cm}$ ), or $13 \%$ (range, $10 \%$ to $18 \%$ ) of the preoperative bone length. The external fixation was in place for a mean of 61.6 days (range, forty-five to 113 days). The mean external fixation index was 15.1 days $/ \mathrm{cm}$ (range, 13.2 to 20.5 days $/ \mathrm{cm}$ ), and the mean healing index was 48.1 days/cm (range, 41.3 to 55.0 days $/ \mathrm{cm}$ ). The target length was achieved in all patients.

There were nine complications, and all resolved prior to the last follow-up visit. There were four superficial pin-track infections, all of which resolved with oral antibiotic treatment. Four patients had joint stiffness during the lengthening, which responded to physiotherapy. No patient had an infection around the plate. All eight of these patients regained a full range of movement. The ninth patient fell during sports activity four months after we removed the external fixator and sustained a fracture of the tibial distraction callus and locking-plate failure. The patient underwent refixation with a longer locking plate and additional screws, and the fracture healed uneventfully.

When they were last seen for follow-up, all ten patients in the study were walking with full, unassisted weight-bearing, had excellent joint motion, and had solid union at the lengthening site. Furthermore, all ten patients had the normal limb alignment that they had had preoperatively, with no rotational or angular deformity or joint laxity.

\section{What to Watch For}

\section{Indications}

- $\quad$ Although lengthening over an intramedullary nail can reduce the external fixation time, it is difficult to perform in skeletally immature patients because of an open physis, a narrow medullary canal, and the possibility of osteonecrosis of the femoral head. Lengthening with a submuscular locking plate technique is a good option for these patients.

- The method may also be useful when nail insertion is difficult, such as in the presence of osseous deformity, joint contracture, or a previous arthroplasty.

Chang-Wug Oh, MD, PhD

Joon-Woo Kim, MD, PhD

Seung-Gil Baek, MD

\section{Contraindications}

- Although, in our opinion, there is no absolute contraindication for this method, a plate is inherently inferior to an intramedullary nail in terms of bending and axial stiffness. Therefore, we prefer not to use a locking plate when an intramedullary nail can be inserted into a medullary canal of sufficient diameter.

\section{Pitfalls \& Challenges}

- When the external fixator is placed, half-pins or wires should not contact the plate or screws, to avoid cross-contamination, which may evolve into deep infection.

- To provide sufficient stability, a longer plate should be chosen unless there is an anatomical restriction. Also, we prefer to use three screws per segment.

- Protection from full weight-bearing and the use of a protective device (such as a patellar tendon bearing brace after tibial lengthening) is recommended until sufficient consolidation of the distraction callus has been achieved.

- When screws are inserted for fixation in skeletally immature patients, they should not intrude upon the epiphyseal plate.

- During Step 3 of the procedure, locking of the distal segment should be performed prior to removal of the external fixator. If the procedures are not performed in this order, distraction callus may be pulled back proximally.

\section{Clinical Comments}

Lengthening with a submuscular locking plate did not disturb the regeneration of distraction callus, and the healing indices achieved were similar to those associated with conventional lengthening without the plate. Our technique can permit earlier removal of the fixator with fewer complications compared with the conventional lengthening method, and it is a useful alternative in children or in patients in whom nailing is difficult. The plate should be strong enough to provide adequate stability until osseous consolidation is achieved after removal of the external fixator. In our clinical experience, the use of a plate of sufficient length, fixed with three or more bicortical screws per segment, provides adequate stability. Because a plate is inherently inferior to an intramedullary nail in terms of bending and axial stiffness, we prefer to use an intramedullary nail when one can be inserted without undue difficulty. 
Hee-Soo Kyung, MD, PhD

Hyun-Joo Lee, MD

Department of Orthopaedic Surgery, Kyungpook National University Hospital, 50, 2-Ga, Samdok, Chung-gu, Daegu, 700-721, Republic of Korea. E-mail address for J.-W. Kim: orthopedics@naver.com

Disclosure: None of the authors received payments or services, either directly or indirectly (i.e., via his or her institution), from a third party in support of any aspect of this work. None of the authors, or their institution(s), have had any financial relationship, in the thirtysix months prior to submission of this work, with any entity in the biomedical arena that could be perceived to influence or have the potential to influence what is written in this work. Also, no author has had any other relationships, or has engaged in any other activities, that could be perceived to influence or have the potential to influence what is written in this work. The complete Disclosures of Potential Conflicts of Interest submitted by authors are always provided with the online version of the article.

\section{References}

1. Ilizarov GA. The principles of the Ilizarov method. Bull Hosp Jt Dis Orthop Inst. 1988 Spring;48(1):1-11.

2. Price CT, Mann JW. Experience with the Orthofix device for limb lengthening. Orthop Clin North Am. 1991 Oct;22(4):651-61.

3. Stanitski DF, Shahcheraghi H, Nicker DA, Armstrong PF. Results of tibial lengthening with the Ilizarov technique. J Pediatr Orthop. 1996 Mar-Apr;16(2):168-72.

4. Zarzycki D, Tesiorowski M, Zarzycka M, Kacki W, Jasiewicz B. Long-term results of lower limb lengthening by the Wagner method. J Pediatr Orthop. 2002 May-Jun;22(3):371-4.

5. Paley D. Problems, obstacles, and complications of limb lengthening by the Ilizarov technique. Clin Orthop Relat Res. 1990 Jan;(250):81-104.

6. Simpson AH, Kenwright J. Fracture after distraction osteogenesis. J Bone Joint Surg Br. 2000 Jul;82(5):659-65.

7. Liu T, Zhang X, Li Z, Zeng W, Peng D, Sun C. Callus distraction for humeral nonunion with bone loss and limb shortening caused by chronic osteomyelitis. J Bone Joint Surg Br. 2008 Jun;90(6):795-800.

8. Zhang X, Liu T, Li Z, Peng W. Reconstruction with callus distraction for nonunion with bone loss and leg shortening caused by suppurative osteomyelitis of the femur. J Bone Joint Surg Br. 2007 Nov;89(11):1509-14.

9. Paley D, Herzenberg JE, Paremain G, Bhave A. Femoral lengthening over an intramedullary nail. A matched-case comparison with Ilizarov femoral lengthening. J Bone Joint Surg Am. 1997 Oct;79(10):1464-80.

10. Gordon JE, Goldfarb CA, Luhmann SJ, Lyons D, Schoenecker PL. Femoral lengthening over a humeral intramedullary nail in preadolescent children. J Bone Joint Surg Am. 2002 Jun;84(6):930-7.

11. Min WK, Min BG, Oh CW, Song HR, Oh JK, Ahn HS, Park BC, Kim PT. Biomechanical advantage of lengthening of the femur with an external fixator over an intramedullary nail. J Pediatr Orthop B. 2007 Jan;16(1):39-43.

12. Kocaoglu M, Eralp L, Kilicoglu O, Burc H, Cakmak M. Complications encountered during lengthening over an intramedullary nail. J Bone Joint Surg Am. 2004 Nov;86(11):2406-11.

13. Simpson AH, Cole AS, Kenwright J. Leg lengthening over an intramedullary nail. J Bone Joint Surg Br. 1999 Nov;81(6):1041-5.

14. Perren SM. Evolution of the internal fixation of long bone fractures. The scientific basis of biological internal fixation: choosing a new balance between stability and biology. J Bone Joint Surg Br. 2002 Nov;84(8):1093-110.

15. Oh CW, Shetty GM, Song HR, Kyung HS, Oh JK, Min WK, Lee BW, Park BC. Submuscular plating after distraction osteogenesis in children. J Pediatr Orthop B. 2008 Sep;17(5):265-9.

16. Oh CW, Song HR, Kim JW, Choi JW, Min WK, Park BC. Limb lengthening with a submuscular locking plate. J Bone Joint Surg Br. 2009 Oct;91(10):1394-9.

\section{Figures}

Fig. 1

An eleven-year old boy had an idiopathic leg-length discrepancy due to tibial shortening of about $32 \mathrm{~mm}$. (Reproduced, with permission and copyright of British Society of Bone and Joint Surgery, from: Oh CW, Song HR, Kim JW, Choi JW, Min WK, Park BC. Limb lengthening with a submuscular locking plate. J Bone Joint Surg Br. 2009 Oct;91[10]:1394-9.)

Fig. 2

After fibular osteotomy, a submuscular locking plate was placed laterally, and four locking screws were fixed to the proximal segment (Figs. 2-A, 2-B, and 2-C). Then, a monolateral external fixator for lengthening was placed medially and 
percutaneous corticotomy was performed (Fig. 2-D).

Fig. 3

Schematic illustration of the postoperative status (Fig. 3-A), a postoperative radiograph (Fig. 3-B), and a clinical photograph (Fig. 3-C). Note that the locking screws and Schanz pin should not intrude upon the physeal plate. (Figs. 3-B and 3-C reproduced, with permission and copyright of British Society of Bone and Joint Surgery, from: Oh CW, Song HR, Kim JW, Choi JW, Min WK, Park BC. Limb lengthening with a submuscular locking plate. J Bone Joint Surg Br. 2009 Oct;91[10]:1394-9.)

Fig. 4

Distraction was performed until the target length was achieved. (Reproduced, with permission and copyright of British Society of Bone and Joint Surgery, from: Oh CW, Song HR, Kim JW, Choi JW, Min WK, Park BC. Limb lengthening with a submuscular locking plate. J Bone Joint Surg Br. 2009 Oct;91[10]:1394-9.)

Fig. 5

After lengthening was done, locking of the distal segment was performed in a percutaneous manner, after which the external fixator was removed.

Fig. 6

Postoperative radiograph (Fig. 6-A) and photograph showing the wound (Fig. 6-B). (Reproduced, with permission and copyright of British Society of Bone and Joint Surgery, from: Oh CW, Song HR, Kim JW, Choi JW, Min WK, Park BC. Limb lengthening with a submuscular locking plate. J Bone Joint Surg Br. 2009 Oct;91[10]:1394-9.)

Fig. 7

Six months later, the distraction callus had healed (Figs. 7-A and 7-B) and the patient had an excellent functional result (Fig. 7-C). (Figs. 7-A and 7-B reproduced, with permission and copyright of British Society of Bone and Joint Surgery, from: Oh CW, Song HR, Kim JW, Choi JW, Min WK, Park BC. Limb lengthening with a submuscular locking plate. J Bone Joint Surg Br. 2009 Oct;91[10]:1394-9.)

Fig. 8

A twenty-nine-year-old woman had femoral shortening of $42 \mathrm{~mm}$ as a result of septic hip sequelae.

Fig. 9

A submuscular locking plate was fixed with a flexible intramedullary nail after corticotomy. Note the three half-pins of the external fixator fixed proximal and distal to the plate.

Fig. 10

After achievement of the target length (Fig. 10-A), screws were fixed percutaneously at the distal segment (Fig. 10-B). The external fixator was removed at this stage.

Fig. 11

Postoperative radiographs (Figs. 11-A and 11-B) and a photograph showing the wound (Fig. 11-C).

Fig. 12

One year later, the distraction callus had healed.

Fig. 13

The lengths of both lower limbs were the same (Fig. 13-A), and the functional result was excellent (Figs. 13-B and 13-C). 


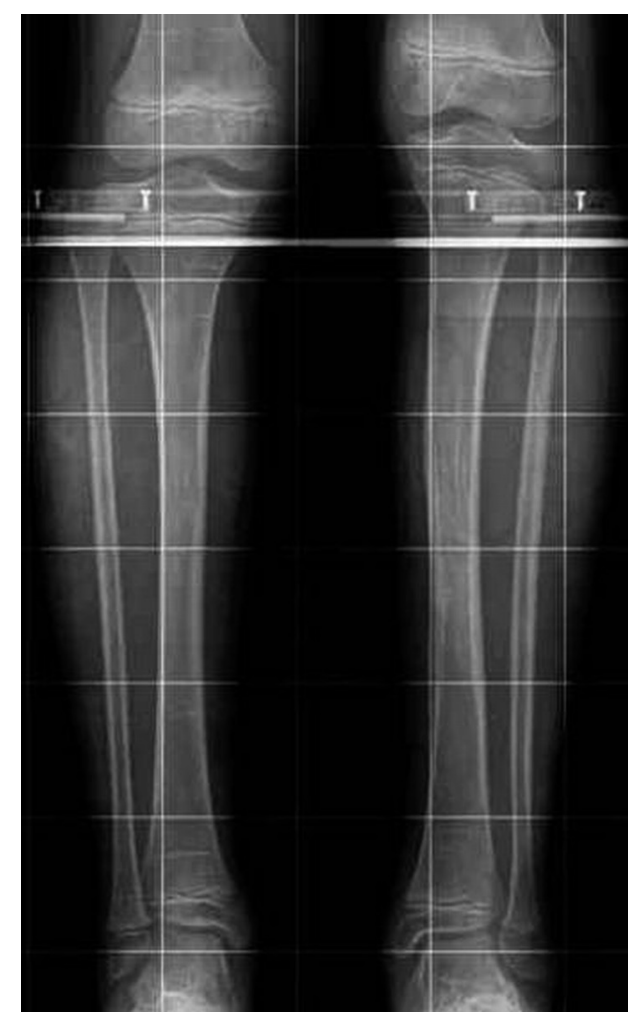

Fig. 1

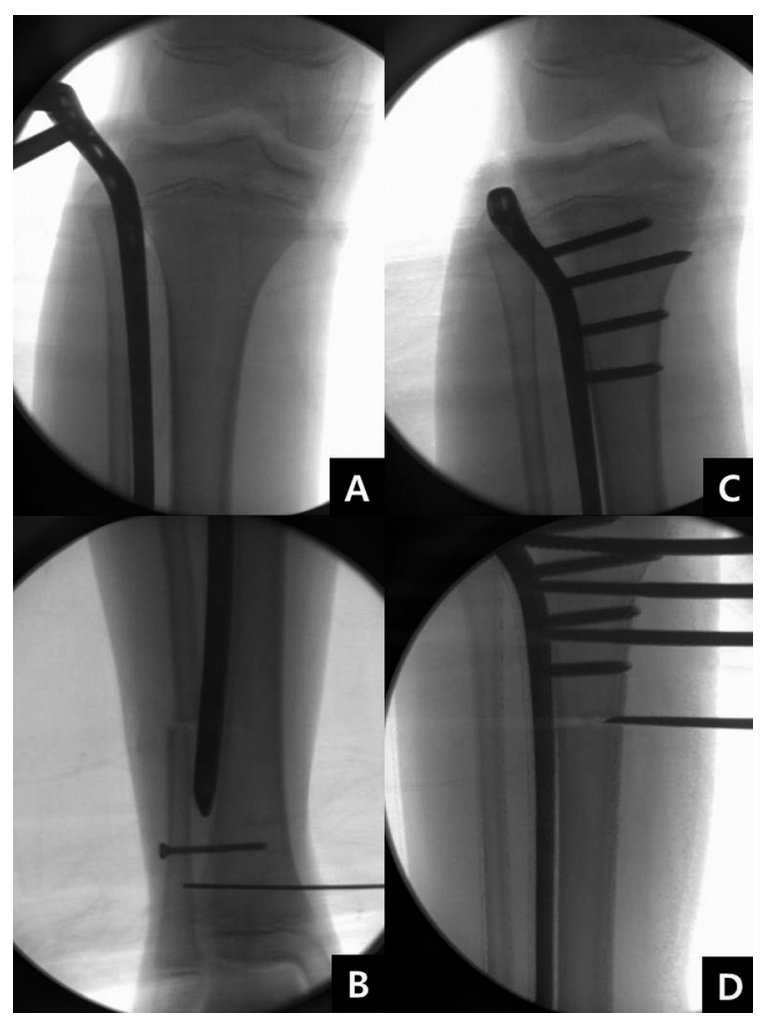

Fig. 2

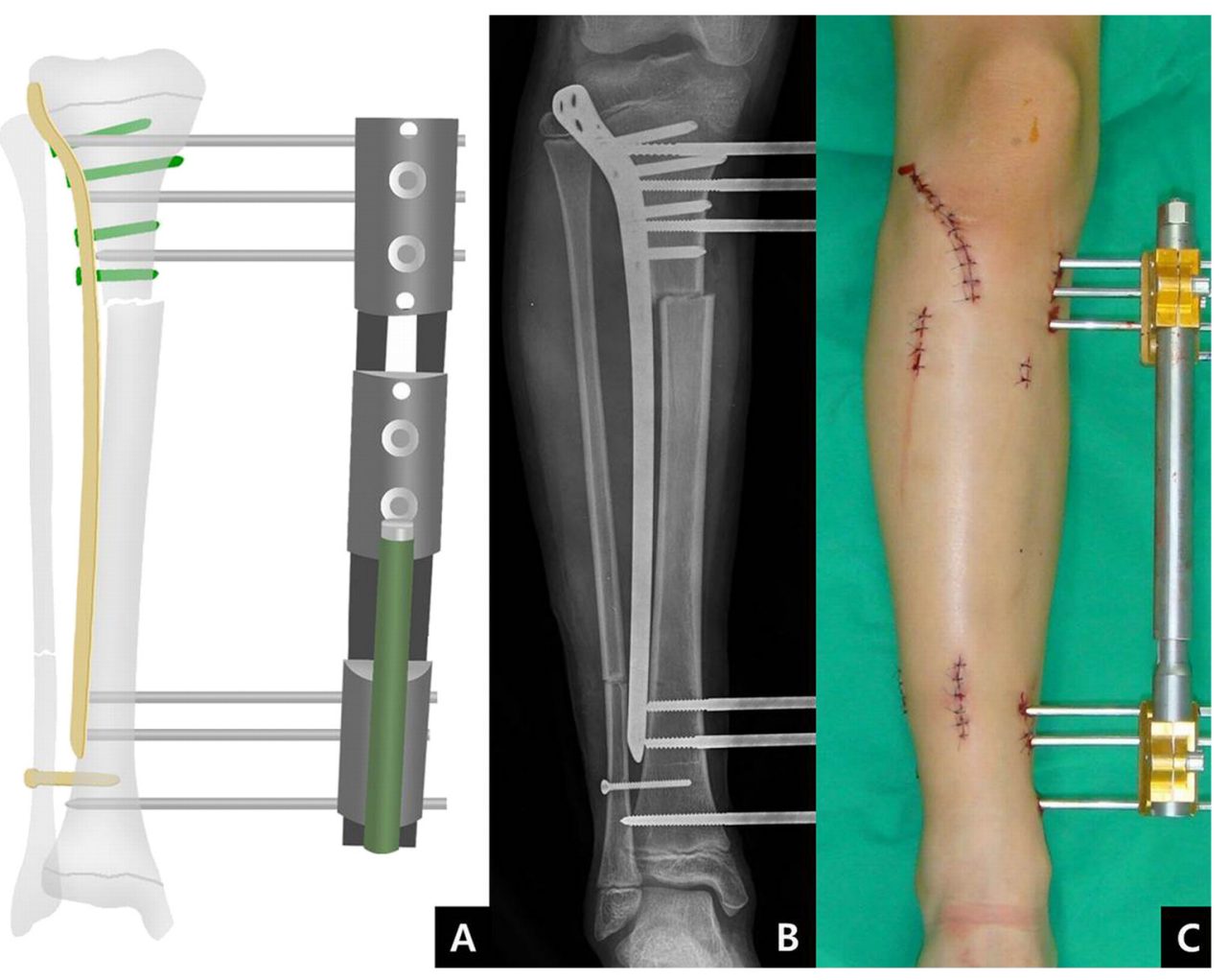

Fig. 3 


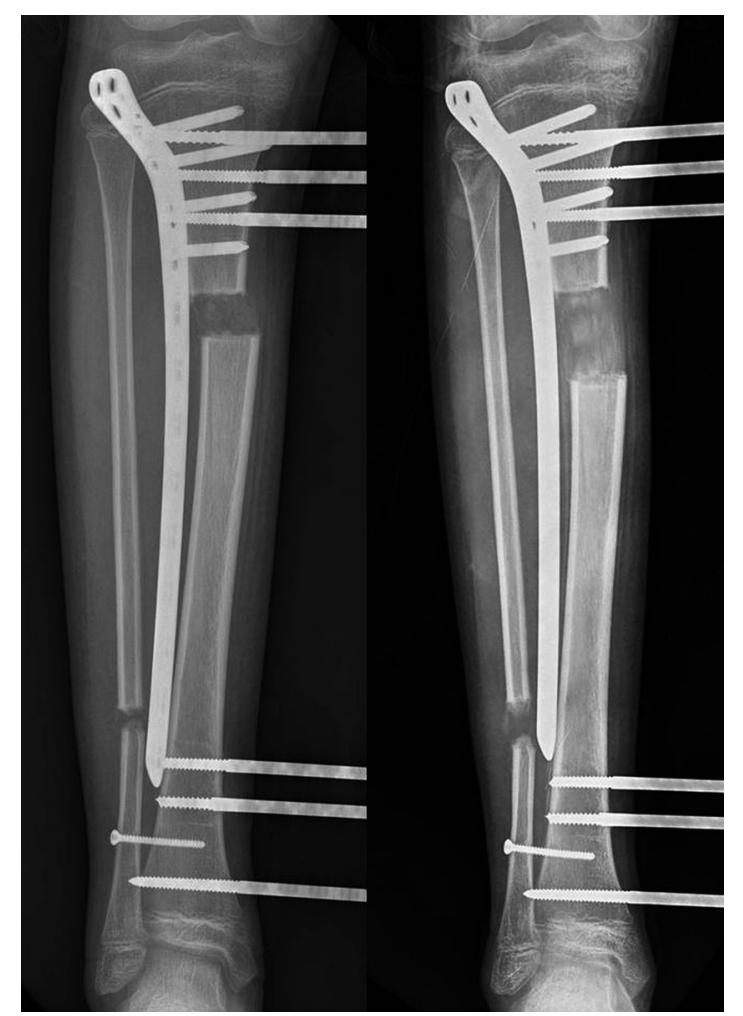

Fig. 4

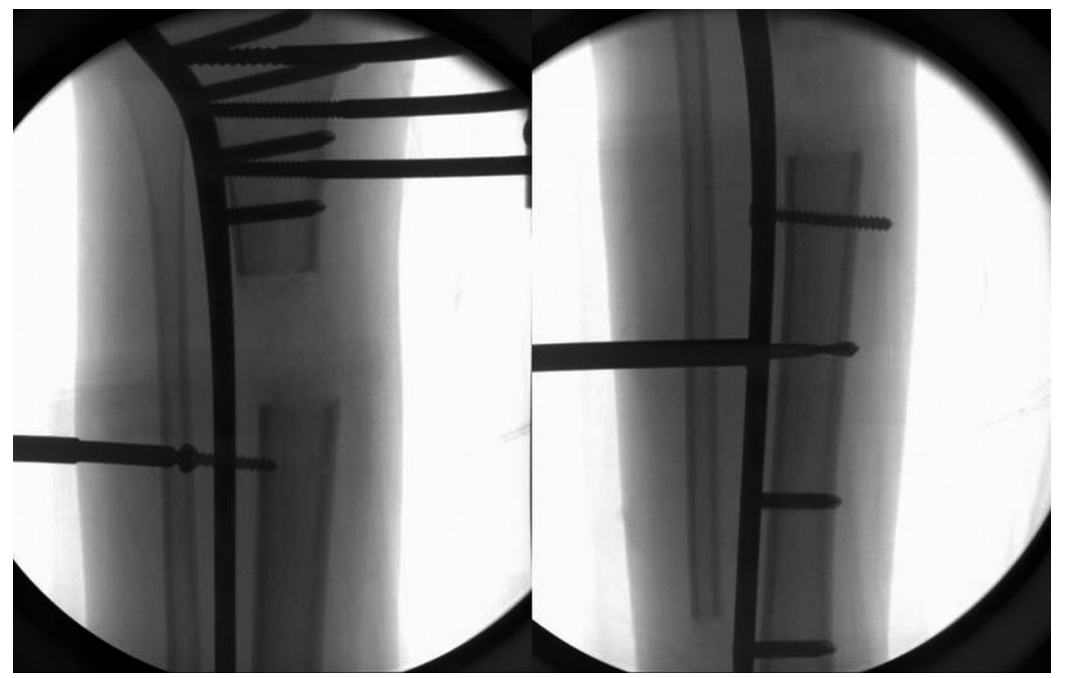

Fig. 5

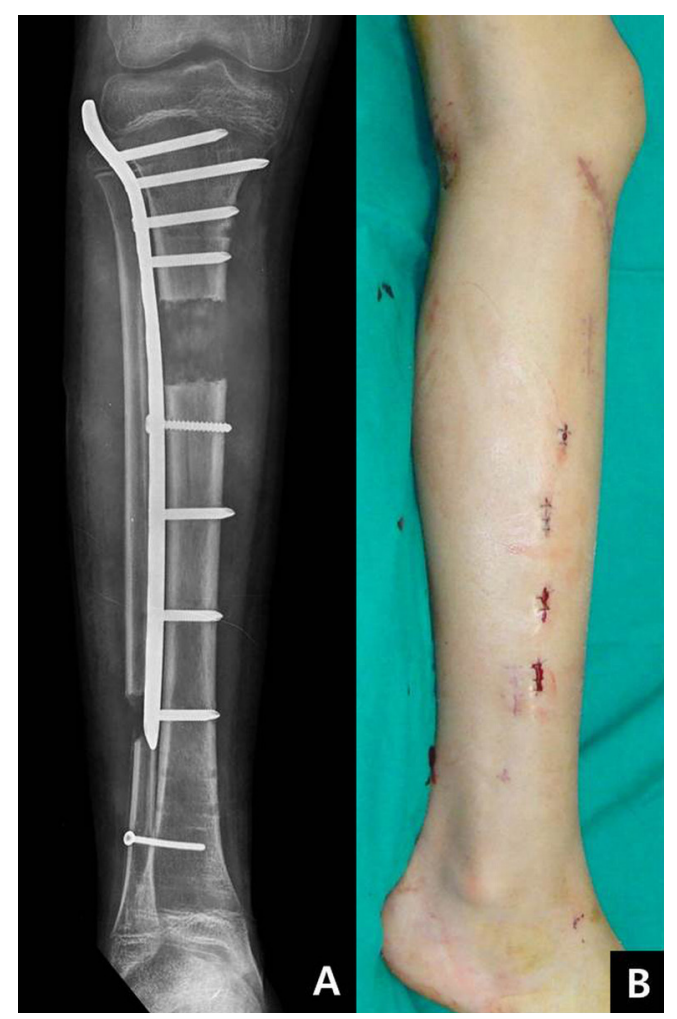

Fig. 6

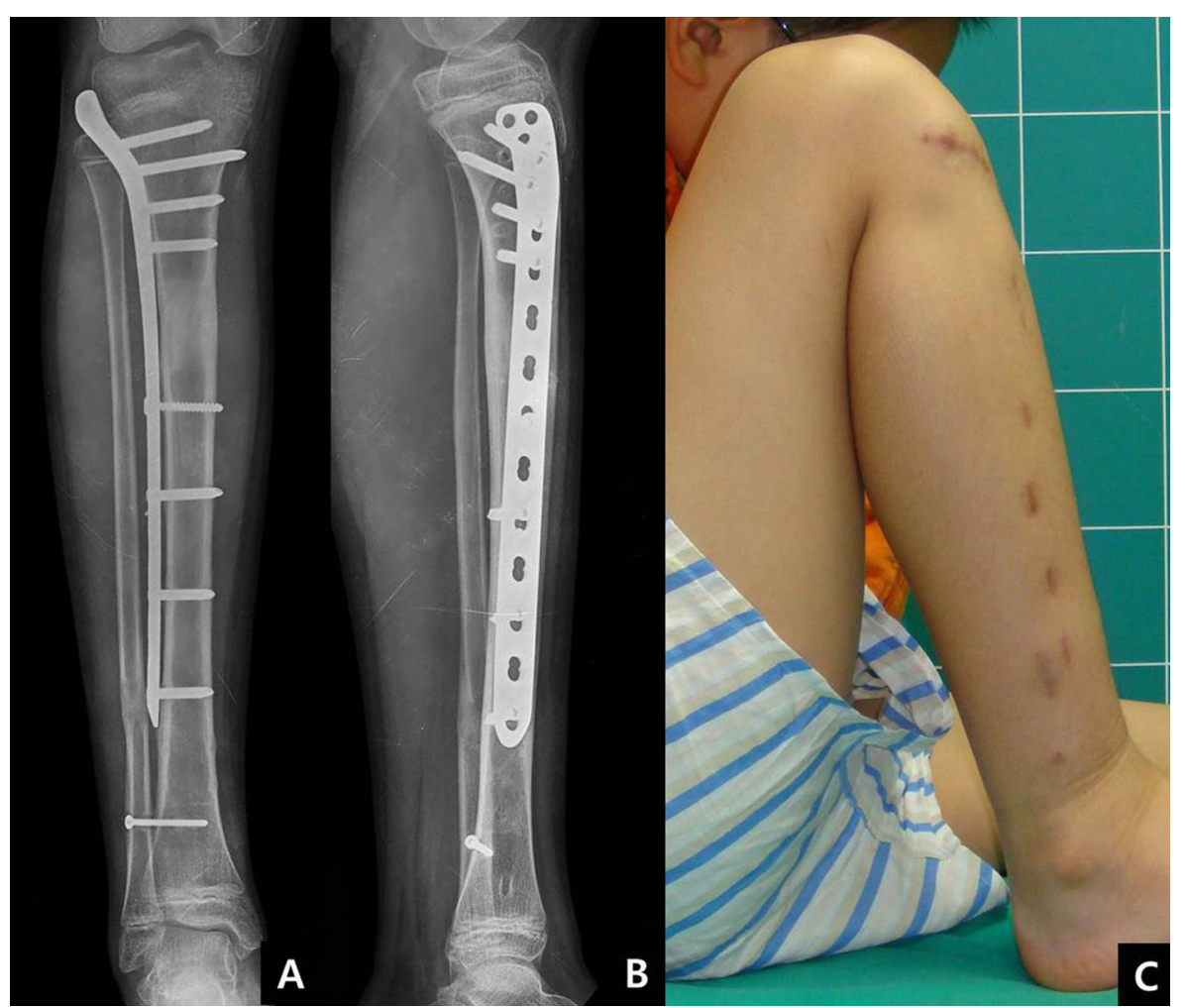

Fig. 7 


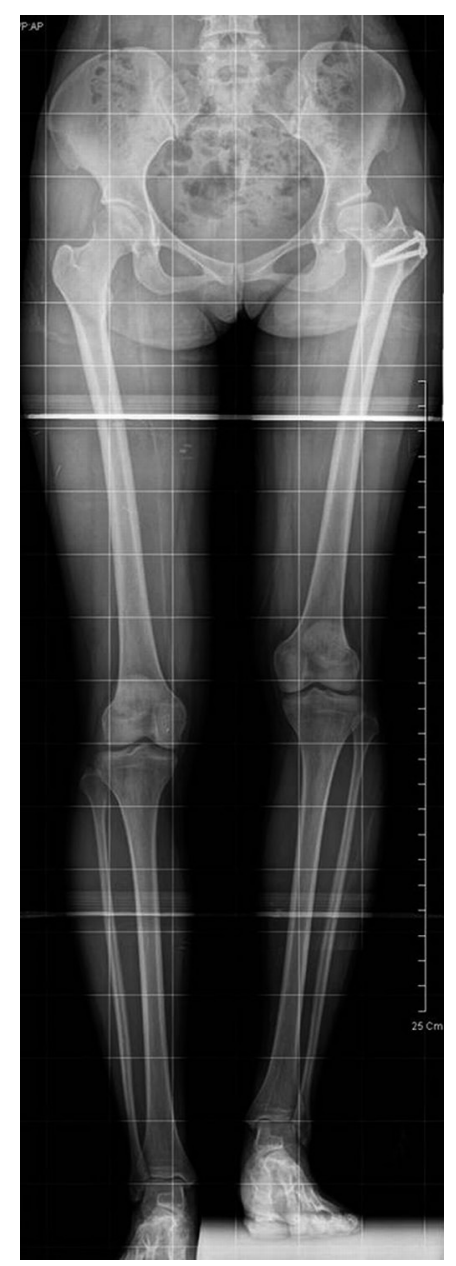

Fig. 8

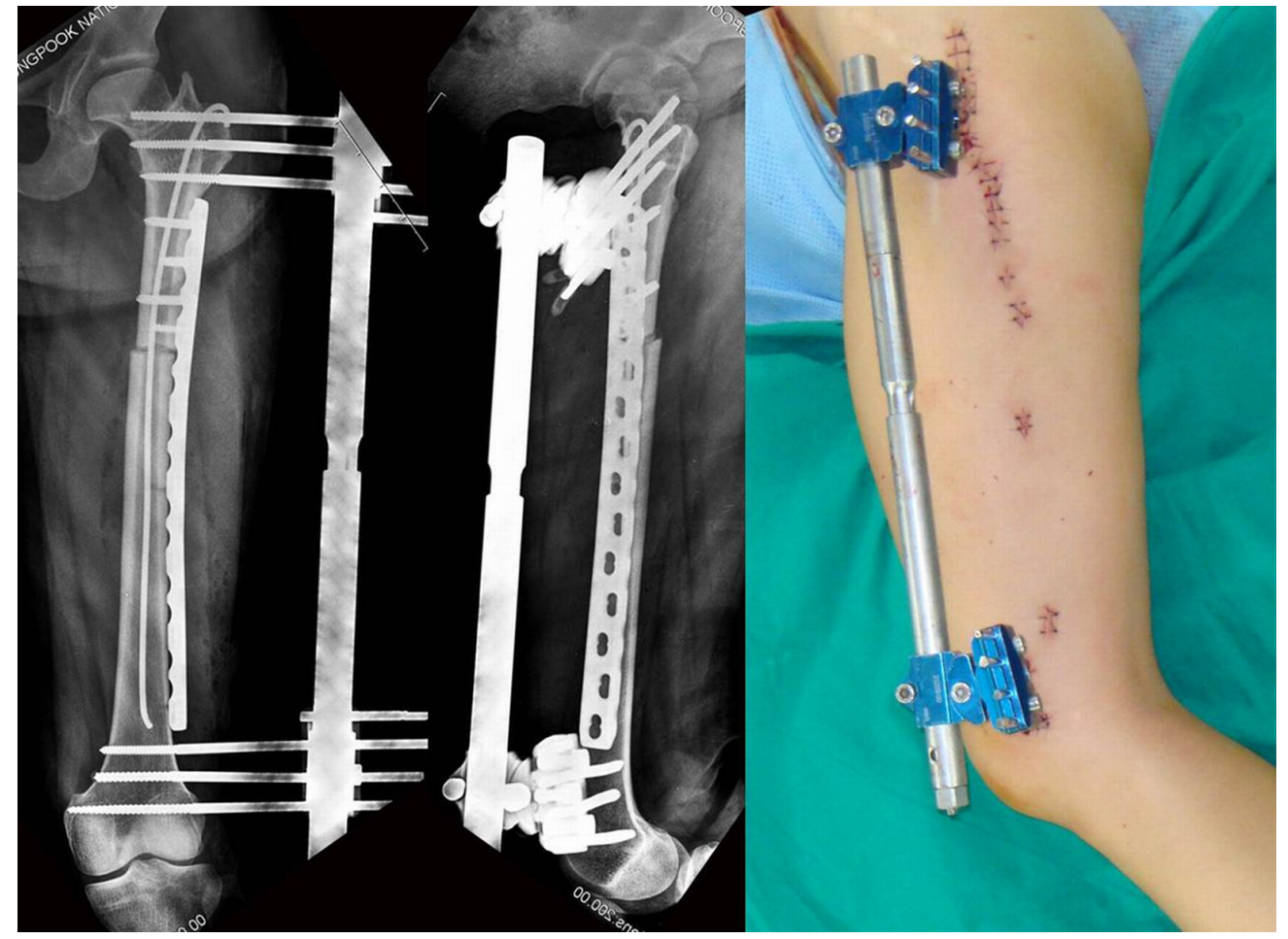

Fig. 9

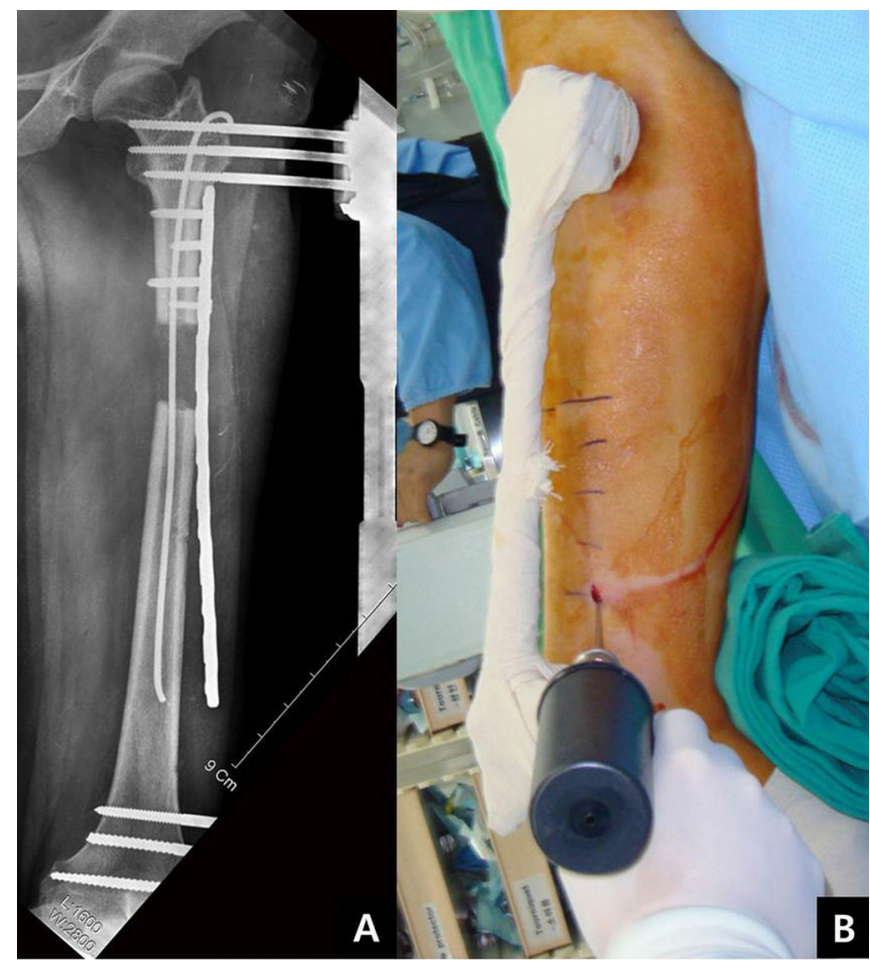

Fig. 10 


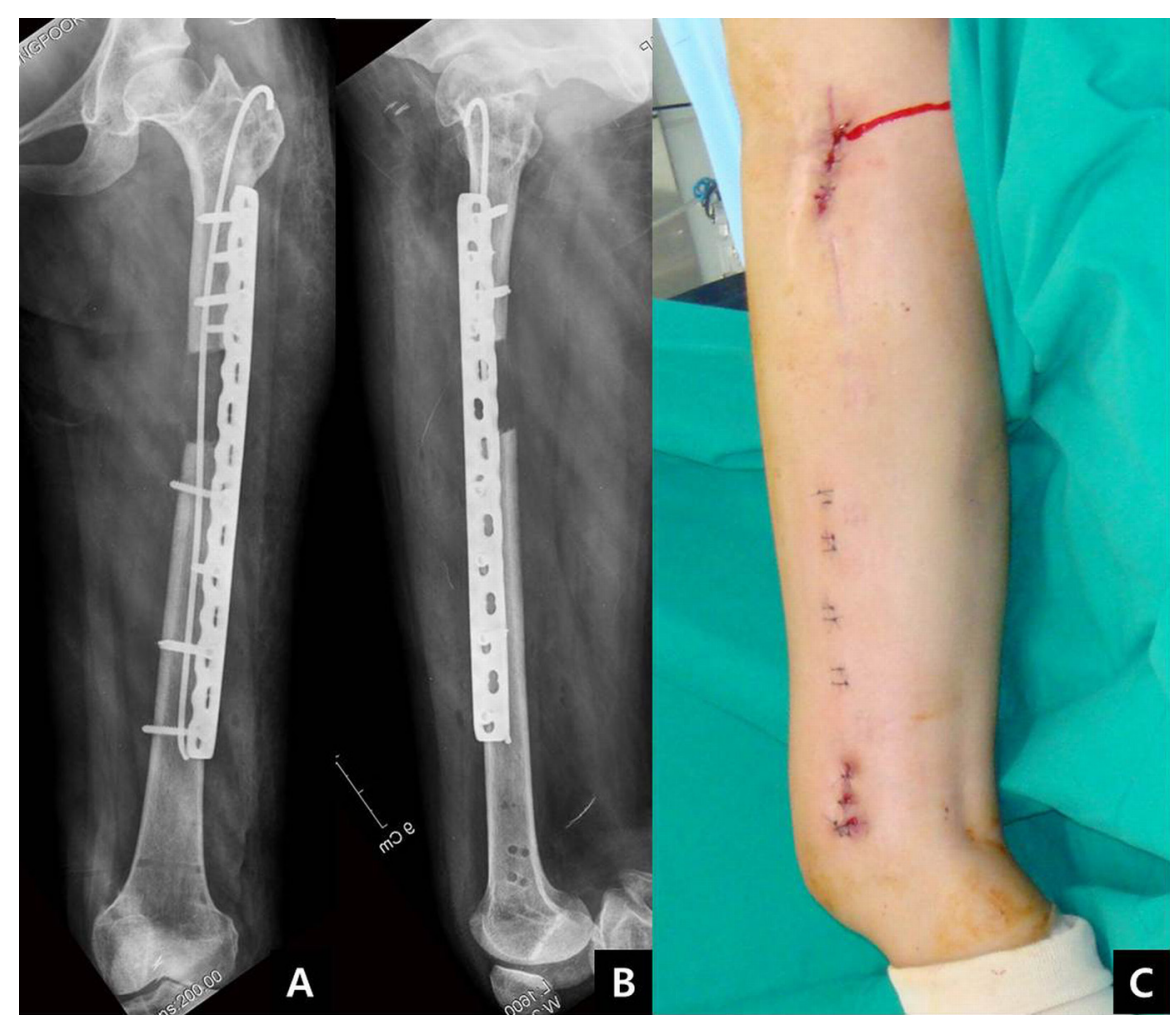

Fig. 11

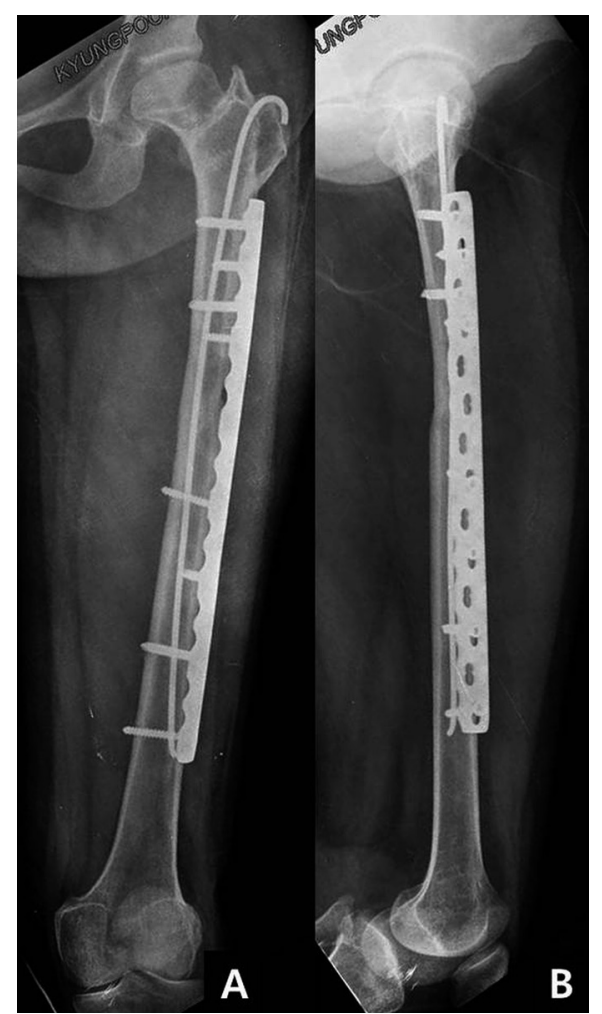

Fig. 12

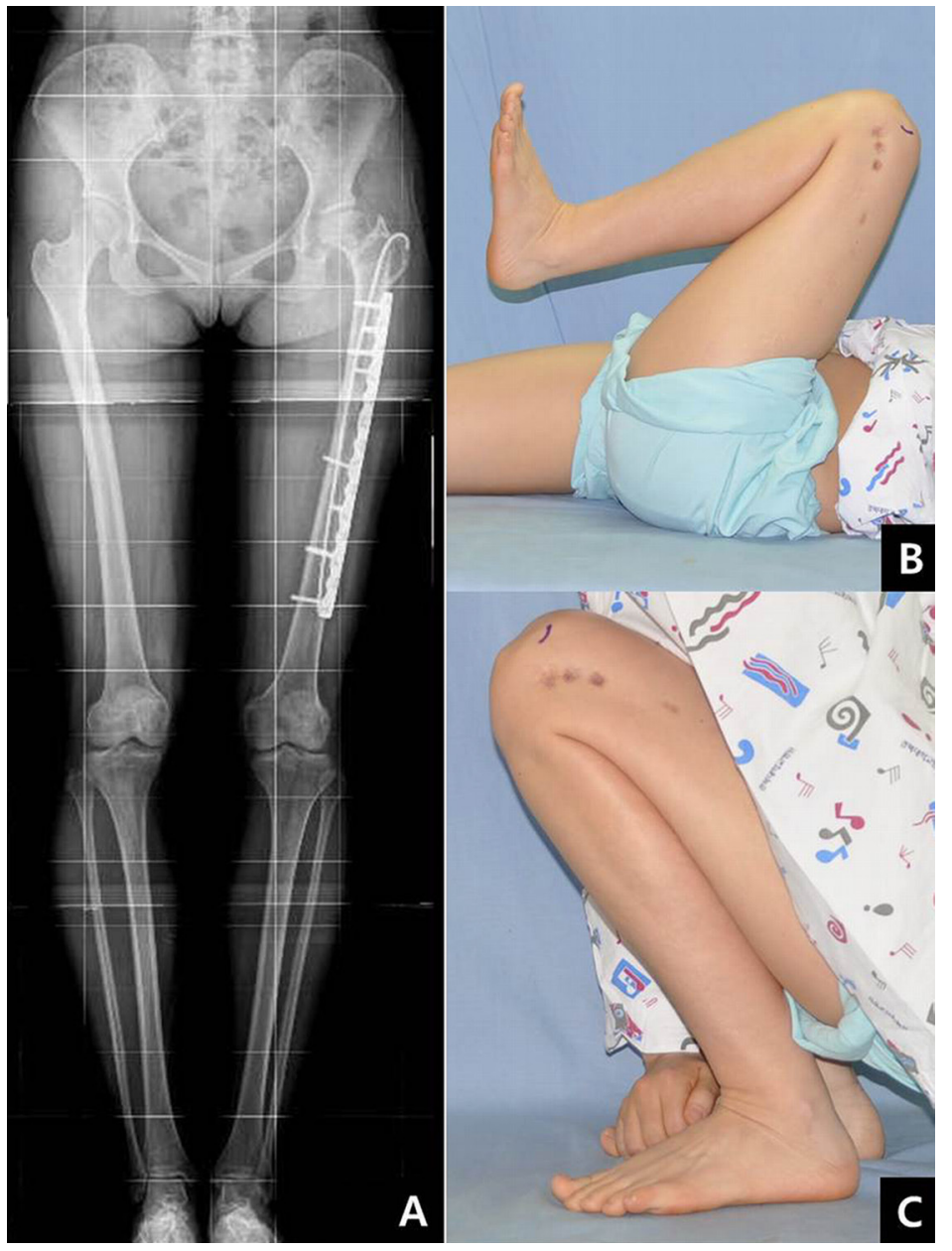

Fig. 13 